\title{
Cannabis and Autoimmunity - The Neurologic Perspective: A Brief Review
}

\author{
Katz $\mathrm{D}^{1,2}$, Katz $\mathrm{I}^{1,2}$, Shoenfeld $\mathrm{Y}^{1,3 *}$ \\ 'The Zabludowicz Center for Autoimmune Diseases, Chaim Sheba Medical Center, Tel-Hashomer, Israel \\ ${ }^{2}$ Faculty of Medicine, The Hebrew University of Jerusalem, Israel \\ ${ }^{3}$ Incumbent of the Laura Schwarz-kipp chair for research of autoimmune diseases, Sackler Faculty of Medicine, Tel-Aviv University, Israel
}

Article Info

\section{Article Notes}

Received: April 26, 2016

Accepted: July 02,2016

\section{${ }^{*}$ Correspondence:}

Dr. Yehuda Shoenfeld MD, FRCP, MaACR

The Zabludowicz Center for Autoimmune Diseases

Chaim Sheba Medical Center

Tel-Hashomer 52621, Israel

Telephone: $972-3-5308070$

Fax: 972-35352855

Email: shoenfel@post.tau.ac.il

(c) 2016 Shoenfeld $Y$. This article is distributed under the terms of the Creative Commons Attribution 4.0 International License

\section{Introduction}

The tale of Cannabis sativa is as old as time. Through its first days as an herbal remedy, ranging back to $4000 \mathrm{BC}$ and to Emperor Shen Nung's Rule (2700 BC), to cannabis low point of being banned internationally at 1925 to its recent re-emergence by prof. Mechoulam isolation of the Tetrahydrocannabinol (THC, 1963), Cannabis is slowly gaining its place in medicine ${ }^{1,2}$.

Cannabis sativa, also known as Marijuana has been called many names, yet the variety of names given to Cannabis does not encompass the vast medical opportunities that lie within the cannabis. As of now, 545 ingredients have been identified, of which over 100 classified as unique to Cannabis ${ }^{3}$. The two main and most researched active ingredients are - Tetrahydrocannabinol (THC) which holds a psychoactive properties and on the other hand, Cannabidiol (CBD) which is considered non psychoactive. The components are joined by the two main known endocannabinoids - Ananamide (AEA) and 2-Arachidonoylglycerol (2-AG) (also discovered by prof. Mechoulam and colleagues $)^{4,5}$. The other half of the cannabinoid system (as we know thus far) comprises of CB1 and CB2 receptors, G-protein coupled receptors. The two receptors differ in distribution and function. While the major psychoactive effect of cannabis is attributed to the CB1 receptor and accordingly widely distributed in neurons, while the $\mathrm{CB} 2$ receptor has been linked to maintaining homeostasis and commonly appears in cells of the immune system ${ }^{6,7}$.

\section{Cannabis and the Brain Immune System}

It is well established that murine microglial cells express both CB1 and $\mathrm{CB} 2$ receptors, yet the pattern of receptors expression differs in location as well as in levels of expression. While CB1 receptor is consistently expressed in microglial cells in low levels, CB2 receptor is indetectable in resting state cells and highly expressed in activated microglia ${ }^{8,9}$. The pattern of expression and distribution of CB2 receptor in microglial cell suggest a role in microglial migration, $\mathrm{CB} 2$ receptor was found to be expressed heterogeneously throughout murine microglial cells with particularly high density at the leading edges of lamellipodia and microspkies (cellular protrusions that mediate cell migration). Moreover, 2-AG, AEA and abnormalcannabidiol increase microglial cell migration ${ }^{10}$. 
Another aspect of the endocannabinoid system effect on microglial cell is the attenuation of the immune response induced by LPS (Lipopolysaccharide) stimulation, AEA attenuates the immediate release of IL-6 and NO by microglial cell by induction of MPK-11 ${ }^{11}$.

A different mechanism of action is suggested by the inhibition of the IL-1 signaling pathway following administration of the synthetic cannabinoid R(+)WIN 55,212-2. Appling R(+)WIN 55,212-2 to astrocytoma cells priori stimulated by IL-1 resulted in dose dependent inhibition of ICAM-1 and VCAM-1 adhesion molecules induction, as well as IL-8 and NFKB. The effect aforementioned is independent from the cannabinoids receptors $\mathrm{CB} 1$ and $\mathrm{CB} 2$ as suggested by the lack of regulation of CB1 and CB2 antagonist on the immunomodulating effects mentioned above, implying that there is still much to learn in the field of Cannabis and immunomodulation ${ }^{12}$.

\section{Cannabis and the Blood-Brain-Barrier}

The blood-brain-barrier (BBB) as well as the bloodspinal cord-barrier (BSCS) and their disturbance is often postulated as a possible mechanism of pathogenesis in neurological autoimmune disease. A possible link of pathogenesis has been suggested in Multiple Sclerosis ${ }^{13}$, Neuromyelitis Optica ${ }^{14}$, Guillain-Barré Syndrome ${ }^{15}$, Chronic Inflammatory Demyelinating Polyneuropathy ${ }^{16}$ and Antiphospholipid Syndrome with neurological involvement ${ }^{17}$.

In murine model of LPS induced vascular and inflammatory changes CBD counteracts the effect of LPS. Mice which received LPS+CBD showed no cerebral vasodilation, no leukocyte migration, reduced TNF- $\alpha$ and COX-2 levels compared to LPS treated mice and more over exhibited reduced dextran extravasation (dextran extravasation is used as a quantification instrument of BBB integrity) ${ }^{18}$.

Similar effect is obtained by administration of Anandamide to TMEV-infected endothelial brain cell. AEA inhibits VCAM-1 induction in vitro, and thus limit leukocyte migration through a transwell filter (coated with collagen type I and fibronectin) model of the BBB. Accordingly, in vivo experiment correlated the result of the in vitro experiments. AEA increased tone (by UCM-707, an AEA uptake inhibitor) inhibited VCAM-1 induced expression, as well as attenuated microglial cell activation ${ }^{19}$.

A role for $\mathrm{CB} 2$ receptor was also exemplified by in vivo murine model. Ex vivo CB2-activted leukocytes were injected to LPS treated mice resulting in adhesion reduction of up to $96 \%$ using GP1a (CB2 receptor agonist) in comparison with to non GP1a treated mice ${ }^{20}$.

The beneficial effect of cannabinoid also extends to human brain endothelial cells (BMVEC). Using human cells from HIV-1 CNS infected patients and from seronegative controls, a group of researches demonstrated enhanced CB2 receptor expression in HIV infected cells compared to controls. Further investigation of naive human BMVEC revealed that the increased expression of CB2 receptor can also be accomplished separately by IL-1 $\beta$, TNF- $\alpha$ and LPS. Once induced and activated, CB2 receptor decreased leukocyte adhesion, prevented up regulation of adhesion molecules, promoted 2.2-2.7 increase in tight junction proteins (occludin and claudin-5) and significantly reduced BBB resistance drop induced by LPS ${ }^{21}$.

The coherence of the above mentioned experiments is also exemplified at the genetic level. Human BMVEC isolated from eleptogenic patients were activated using TNF- $\alpha$ to evaluate consequent gene expression. Out of 33 genes that were up regulated by TNF- $\alpha, 31$ and 32 genes were suppressed using CB2 agonist 0-1966 or JWH-133 respectively ${ }^{22}$.

Cannabinoids protective effect goes beyond the BBB and also extends to the BSCB. Pretreatment by JHW-015, a CB2 receptor agonist prevents down regulation of occludin and ZO-1 induced by spinal cord ischemia reperfusion injury (SCII) in murine in vivo model. Moreover, JWH-015 pretreatment reduces BBB leakage (measured by Evans blue) compared to SCII only group ${ }^{23}$.

Cannabis potential ability to protect BBB integrity is of possible great importance, not only in autoimmune neurologic disorders, but in a vast verity of neurological fields as in Alzheimer's disease and ischemia injury.

\section{Cannabis and Autoimmune Demyelinating Disease}

Multiple Sclerosis (MS) is known as the hallmarks of neurological autoimmune disease with prevalence as high as 200:100,000 in some countries in northern Europe ${ }^{24}$.

MS Patients are characterized by high CSF levels of AEA compared to healthy control. In accordance high levels of AEA were also measured in autoimmune encephalomyelitis (EAE), a murine model of MS. Moreover, increased NAPEPLD (part of AEA production) activity and reduced FAAH (degrades AEA) activity ${ }^{25}$. CB1 receptor deficient mice exhibit substantial neurodegeneration following EAE induction including higher prevalence of residual paresis and axonal pathology in relation to wild type mice ${ }^{26}$.

CBD treatment of TMEV infected mice induces a wide range of immunomodulatory outcomes. CBD reduce the infiltrate of immune cell to the brain parenchyma and decreased microglial activation. Moreover, CBD treatment has a long lasting effect, an 80 days follow up of the treatment group revealed restoration of both horizontal and vertical motor activities to that of the healthy mice and a correlating reduction in the expression of TNF- $\alpha$ and IL$\beta 1^{27}$. 
MS is positively influenced by a variety of cannabinoids, both natural and synthetic, each demonstrating a different mechanism of action to our knowledge. Among the different cannabinoids we can find Cannabidiol which holds the ability to attenuate a range of neuronal apoptotic pathways ${ }^{28}$, Cannabigerol Quinone which its application on murine neuronal culture results in inhibition of IL-1 $\beta$, IL-6 and PGE2 release ${ }^{29}$. Also Gp1a, a selective CB2 receptor agonist that modulates EAE development by reducing Th17 differentiation ${ }^{30}$, HU-446 and HU-465 (CBD derivatives) and many more which we won't elaborate on ${ }^{31}$.

There is scarce evidence regarding clinical use of Cannabis in MS patients. A recent Meta-analysis concluded that cannabinoids (nabilone and nabiximols) were associated with a greater average improvement in spasticity assessed by using numerical rating scale (mean difference, -0.76 [ $95 \% \mathrm{CI},-1.38$ to -0.14$]$ ). Also, the average number of patients who reported an improvement on a global impression of change score was greater using nabiximols rather placebo (OR, 1.44 [95\% CI, 1.07-1.94]) $)^{32}$. Notably, a new large multi centered blinded study was recently published, in which 489 MS patients participated and received either oral dronabinol (THC) or placebo. The study failed to prove the beneficial outcome of dronabinol use in two main outcomes (time to confirmed EDSS [Extended Disability Status Scale] score progression and change in MSIS-29 [Multiple Sclerosis Impact Scale-29] score). However, while taking into consideration the results of this trail, it is worth mentioning a possible weakness in the trail inclusion criteria. The disease progression in MS as measured by the EDSS scale is not linear, and progression through EDSS 4-5.5 is faster the in EDSS 6-6.6. hus making the EDSS 6+ patient's population insensitive to treatment during the study period of time, leaving the question of Cannabis medical use in MS patients in need of further research $^{33,34}$. Currently, evidenced based recommendation published in 2014 by the American academy of neurology are: oral cannabis extracts (CBD/THC or CBD alone) are the

\begin{tabular}{|c|c|c|c|}
\hline System & Adverse Effect & Statistics $^{\mathrm{a}}$ & References \\
\hline Neurologic & $\begin{array}{c}\downarrow \text { hippocampus \& amygdala volumes } \\
\uparrow \text { Incidence of acute ischemic stroke } \\
\text { Age } 15-54 \\
\text { Age } 25-34 \\
\text { Age } 45-54 \\
\text { Drowsiness } \\
\text { Dizziness } \\
\downarrow \text { Educational performance (adolescents) } \\
\text { Lower IQ }\end{array}$ & $\begin{array}{l}\text { RR } 1.13(1.11-1.15)^{*} \\
\text { RR } 2.26(2.14-2.38)^{*} \\
\text { RR } 1.45(1.42-1.54)^{*} \\
\text { OR } 3.68(2.24-6.01)^{*} \\
\text { OR } 5.09(4.10-6.32)^{*} \\
\downarrow 11 \%(\% \text { GCSE }+ \text { points)* } \\
\text { Linear trend, t test } \\
\text { t: }-3.36^{* * *}\end{array}$ & $32,40-43$ \\
\hline Psychiatric & $\begin{array}{c}\text { Psychosis } \\
\text { Schizophrenia } \\
\text { Anxiety } \\
\text { Depression }\end{array}$ & $\begin{array}{c}\text { OR } 1.41(1.20-1.65)^{*} \\
\text { OR } 1.9(1.1-3.1)^{*} \\
\text { OR } 1.98(0.73-5.35)^{*} \\
\text { OR } 1.49(1.15-1.94)^{*}\end{array}$ & $32,44,45$ \\
\hline Cardiovascular & $\begin{array}{l}\text { Tachyarrhythmia } \\
\text { Palpitation } \\
\text { Angina }\end{array}$ & $\begin{array}{c}\text { RR 1.5 (1.1-2.1)* } \\
\downarrow 48 \%(\downarrow \text { time to, during exercise })^{* *}\end{array}$ & $38,46,47$ \\
\hline $\begin{array}{l}\text { Pulmonary } \\
\text { (cannabis smoking) }\end{array}$ & $\begin{array}{l}\text { Chronic Bronchitis symptoms } \\
\text { 个health services for respiratory infections }\end{array}$ & $25 \%-33 \%$ of smokers & 46,48 \\
\hline Gastrointestinal & $\begin{array}{c}\text { Nausea } \\
\text { Diarrhea } \\
\text { Vomiting } \\
\text { Abdominal pain } \\
\text { Constipation }\end{array}$ & $\begin{array}{l}\text { OR } 2.08(1.63-2.65)^{*} \\
\text { OR } 1.65(1.04-2.62)^{*} \\
\text { OR } 1.67(1.13-2.47)^{*}\end{array}$ & $32,49,50$ \\
\hline General & Dry mouth & OR $3.50(2.58-4.75)^{*}$ & 32,38 \\
\hline Cannabis dependence & $\begin{array}{l}\text { Adults, Adolescents } \\
\text { Anxiety } \\
\text { Insomnia } \\
\text { Appetite disturbance } \\
\text { Depression } \\
\text { Irritability }\end{array}$ & $\begin{array}{l}9 \%, 17 \% \text { (percentage of users who will } \\
\text { become addicted) }\end{array}$ & 51 \\
\hline Pregnancy & $\begin{array}{l}\text { Maternal anemia } \\
\text { Decrease birth weight } \\
\text { 个Intensive care unit }\end{array}$ & $\begin{array}{l}\text { pOR } 1.36(1.1-1.69)^{*} \\
\text { pOR } 1.77(1.04-3.01)^{*} \\
\text { pOR } 2.02(1.27-3.21)^{*}\end{array}$ & 52 \\
\hline
\end{tabular}

Table 1: ${ }^{\text {a }}$ Statistic differ is amount and substance used.

$* 95 \% \mathrm{Cl}^{* *} \mathrm{p}<0.001 * * * \mathrm{p}$ value: 0.0009

† RR : relative risk; OR : odds ratio; GCSE : General Certificate of Secondary Education; pOR : prevalence odds ratio; $\mathrm{Cl}$ : confidence interval 
only products with an A - effective rating, next in line is THC (dronabinol/nabilone) with B rating- probably effective ${ }^{35}$.

Another demyelinating autoimmune disease that shows promise for cannabis treatment is Neuromyelitis Optica (NMO). Plasma levels of 2-AG were found to be elevated in NMO patients compared to healthy patients. Moreover, 2-AG levels were negatively correlated with pain sensitivity, while AEA correlated positively with pain sensitivity ${ }^{36}$.

Multiple Sclerosis and Neuromyelitis Optica are the milestones of medical cannabis implantation in neurologic autoimmune disease, yet only the foundation has been accomplished up to now and further clinical investigation is the core of establishing Cannabis Sativa and its products as a new therapeutic solution.

\section{Cannabis Adverse Effects}

Cannabis addiction is one of the main adverse effects of chronic cannabis use, though once considered as only "psychological addiction", recent evidence revels a physiological ingredient to the addiction ${ }^{37}$. Epidemiological studies indicate that about $9 \%$ of adult marijuana users will develop cannabis addiction, while adolescent's percentages of addiction is as high as $17 \%{ }^{38}$.

Another adverse effect of great importance lurking chronic cannabis users is the consequence anatomical changes, a 2013 meta-analysis concluded that chronic cannabis consumption results in reduction of hippocampal grey mater ${ }^{39}$. Accordingly a new research conducted at 2015 demonstrated reduced hippocampus and amygdala volumes ${ }^{40}$.

Acute adverse effects (some may be found beneficial in some indications) include anxiety, dysphoria, psychosis/ hallucinations, tachycardia, and stimulation of appetite ${ }^{39}$. Further side effects are listed in table 1.

\section{Conclusion}

Nowadays Cannabis tends to be considered as a "buzz word", with global recognition of the potential embodied in medical Cannabis, more and more countries legalize the use of medical cannabis, leaving many physicians overwhelmed due to the rapid changes. In this article we aimed to review the laboratory and clinical evidence regarding Medical Cannabis and neurological autoimmunity diseases.

Unfortunately, lack of clinical data prevents a definitive conclusion. Nonetheless, clinical trials conducted upon MS and NMO patients suggests a future role for medical cannabis in MS and NMO treatment by obtaining relief in patient symptoms. Yet, the trails aforementioned only paves the beginning, much research is yet to be done in order to evaluate the therapeutic effects of cannabis in treating autoimmune neurologic diseases versus.

Another promising aspect is cannabis protective effect on the BBB, having great potential not only in the field of autoimmunity but also in a variety of other pathologies with attributed BBB damage pathogenesis. The field of cannabis immunomodulation and BBB protection is an exciting new medical pathway, but only further research is to say what will be Cannabis sativa place in medical history.

\section{Abbreviations}

THC : Tetrahydrocannabiol; CBD : Cannabidiol; AEA : Ananamide; 2-AG : 2-Arachidonoylglcerol; LPS : Lipopolysaccharide; IL-6: Interleukin 6; NO : Nitric oxide; MPK1 : Mitogen-activated protein kinase 1; IL-1 : Interleukin 1; ICAM-1: Intercellular Adhesion Molecule 1; VCAM-1 : vascular cell adhesion molecule 1; IL-8 : Interleukin 8; NFKB : Nuclear factor kappa-light-chain-enhancer of activated B cells; BBB : Blood - brain - barrier; BSCB : Blood - spinal cord - barrier; TNF- $\alpha$ : Tumor necrosis factor $\alpha$; COX-2 : Cyclooxygenase-2; TMEV : Theiler's Murine Encephalomyelitis Virus.

\section{References}

1. Pain S. A potted history. Nature. 2015; 525(7570): S10-S11

2. Warf B. High points: An historical geography of Cannabis. Geographical Review. 2014; 104(4): 414-438

3. ElSohly MA, Gul W, Pertwee RG. Handbook of Cannabis: Constituents of Cannabis sativa. Oxford Scholarship Online: Oxford University Press; 2014. Oxford Scholarship Online

4. Devane, WA, Hanus L, Breuer A, et al. Isolation and structure of a brain constituent that binds to the cannabinoid receptor. Science 1992;258(5090):1946-1949.

5. Mechoulam R, Ben-Shabat, S, Hanus L, et al. Identification of an endogenous 2-monoglyceride, present in canine gut, that binds to cannabinoid receptors.Biochemical pharmacology. 1995; 50(1): 83-90.

6. Maccarrone M, Bab I, Bíró T, et al. Endocannabinoid signaling at the periphery: 50 years after THC. Cell Press. 2015; 36(5): 277-276

7. Mechoulam R. Cannabis - the Israeli perspective. J Basic Clin Physiol Pharmacol. 2015; e0091

8. Carlisle SJ, Marciano-Cabral F, Staab A, et al. Differential expression of the CB2 cannabinoid receptor by rodent macrophages and macrophage-like cells in relation to cell activation. International immunopharmacology. 2002; 2(1): 69-82

9. Cabral GA, Raborn ES, Griffin L, et al. $\mathrm{Cb} 2$ receptors in the brain: role in central immune function. Bri J Pharmacol. 2008; 153: 240-251

10.Walter L, Franklin A, Witting A, et al. Nonpsychotrophic cannabinoid receptors regulate microglial cell migration. J Neurosci. 2003; 23(4): 1398-1405

11.Eljaschewitsch E, Witting A, Mawrin C, et al. The endocannabinoid Anandamide protects neurons during CNS inflammation by induction of MPK-1 in microglial cells. Neuron. 2006; 49: 67-79

12. Curran NM, Griffin BD, O’Tolle D, et al. The synthetic Cannabinoid R(+) WIN 55,212-2 inhibits the Interleukin-1 signaling pathway in human astrocytes in a cannabinoid receptor-independent manner. J Biol Chem. 2005; 280 (43): 35797-35806

13.Alvarez JI, Saint-Laurent 0, Godschalk A, et al. Focal disturbances in the blood-brain barrier are associated with formation of neuroinflammatory lesions. Neurobiol Dis. 2015; 74: 14-24

14.Aubé B, Lévesque SA, Paré A, et al. Neutrophils mediate blood-spinal cord barrier disruption in demyelinating neuroinflammatory diseases. J Immunol. 2014; 193(5): 2438-3454 
15. Popescu BF, Lucchinetti CF. Pathology of demyelinating diseases. Annu Rev Pathol. 2012; $7:$ 185-217

16. Isolated blood-cerebrospinal fluid barrier dysfunction: prevalence and associated diseases. J Neurol. 2005; 259(9): 1067- 1073

17. Katzav A, Sohenfeld Y, Chapman J. The pathogenesis of neural injury in animal models of the antiphospholipid syndrome. Clinc Rev Allerg Immunol. 2010; 38: 196-200

18. Ruiz-Valdepeñas L, Martínez-Orgado J, Benito C, et al. Cannabidiol reduce lipopolysaccharide-induced vascular changes and inflammation in the mouse brain: an intravital microscopy study. Journal of Neuroinflammation. 2011; 8(1): 5

19. Meste L, Iñigo PM, Mecha M, et al. Anandamide inhibits Theile's virus induced VCAM-1 in brain endothelial cells and reduces leukocyte transmigration in a model of blood brain barrier by activation of CB1 receptors. Journal of neuroinflammation. 2011; 8: 102

20. Rom S, Zuluaga-Ramirez, Dykstra $\mathrm{H}$, et al. Selective activation of cannabinoid receptor 2 in leukocytes suppresses their engagement of the brain endothelium and protects the blood-brain-barrier. Am J Pathol. 2013; 186(5): 1548-1558

21. Ramirez S.H., Haskó J, Skuba A, et al. Activation of cannabioid receptor 2 attenuates leukocyte-endohelial interactions and blood-brainbarrier dysfunction under inflammatory conditions. J neurosci. 2012; 32(12): 4004-4016

22. Persidsky Y, Fan S, Dykstra H, et al. Activation of cannabinoid type two receptors (CB2) diminish inflammatory response in macrophages and brain endothelium. J neuroimmune Pharmacol. 2015; 10(2): 302-308

23. Yang $M$, Zhang $H$, Wang $Z$, et al. The molecular mechanism and effect of cannabinoid-2 receptor agonist on the blood-spinal cord barrier permeability induced by ischemia-reperfusion injury. Brain research 1636. 2016; 81-92

24. Shapira Y, Agmon-Levin N, Shoenfeld Y. Defining and analyzing geoepidemiology and human autoimmunity. Journal of Autoimmunity. 2010; 34: 168-177

25. Centozne D, Bari M, Prosperetti C, et al. The endocannabinoid system is dysregulated in multiple sclerosis and in experimental autoimmune encephalomyelitis. Brain. 2007; 130: 2543-2553

26. Pryce G, Ahmed Z, Hankey JRH, et al. Cannabinoids inhibit neurodegeneration in models of multiple sclerosis. Brain. 2003; 126: 2191-2202

27. Mecha M, Feliú A, Iñigo PM, et al. Cannabidiol provides long-lasting protection against the deleterious effects of inflammation in a viral model of multiple sclerosis: A role for A2A receptors. Neurology of Disease. 2013; 59: 141-150

28. Giacoppo S, Soundara Rajan T, Galuppo M, et al. Purified cannabidiol the main non-psychotropic component of Cannabis sativa, alone, counteracts neuronal apoptosis in experimental multiple sclerosis. Eur Rev Med Pharmacol Sci. 2015; 19: 4906-4919

29. Granja AG, Carrillo-Salinas F, Pagani A, et al. A cannabigerol quinone alleviates neuroinflammation in chronic model of multiple sclerosis, Neuroimmune Pharmacol. 2012; 7: 1002-1006

30. Kong W, Li H, Tuma RF, Ganea D. Selective CB2 receptor activation ameliorates EAE by reducing TH17 differentiation and immune cell accumulation in the CNS. Cell Immunol. 2014; 287(1): 1-17

31. Kozela E, Haj C, Hanuš L, et al. HU-446 and HU-465, derivatives of the Non-psychoactive cannabinoid cannabidiol, decrease the activation of encephalitogenic T cells. Chem Biol Drug Des. 2016; 87: 143- 153

32. Whiting PF, Wolff RF, Deshpande S, et al. Cannabinoid for medical use a systematic review and meta-analysis. JAMA. 2015; 313(24): 24562473

33.Zajicek J, Ball S, Wright D, et al. Effect of dronabinol on progression in progressive multiple sclerosis (CUPID): a randomized, placebocontrolled trial. Lancent Neurol. 2013; 12(9): 857- 865

34.Pyrce G and Baker D. Cannabinoids fail to show evidence of slowing down the progression of multiple sclerosis. Evid Based Med. 2015; 20(4): 124-124

35. Koppel BS, Brust JCM, Fife T, et al. Systematic review: efficacy and safety of medical marijuana in selected neurologic disorders report of the guideline development subcommittee of the American academy of neurology. Neurology. 2014; 82(17): 1556-1563

36. Pellkofer HL, Havla J, Hauer D, et al. The major Brain endocannabinoid 2-AG controls neuropathic pain and mechanical hyperalgesia in patients with Neuromyelitis Optica. Plos One. 2013; 8(8): e75100

37.Shoenfeld N, Bodnik D, Rosenberg 0, et al. Six-month follow-up study of drugs treatment for cannabis addiction: comparison study of four drugs. Harefuah. 2011; 150(12): 888-892

38. Schort RJ, Hubbard JR. Cannabinoids: Medical implications. Annals of Medicine. 2016; 48(3): 128-141

39. Rocchetti M, Crescini A, Borgwardt S, et al. Is cannabis neurotoxic for the healthy brain? A meta-analysis review of structural brain alterations in non-psychotic users. Psychiatry Clin Neurosci. 2013; 67: 483-492

40.Lorenzetti V, Solowij N, Whittle S, et al. Gross morphological brain changes with chronic, heavy cannabis use. Br J Psychiatry. 2015; 206(1): 77-8.

41. Rumalla K, Reddy AY, Mittal MK. Recreational marijuana use and acute ischemic stroke: a population-based analysis of hospitalized patients in the United States. Journal of neurological Sciences. 2016; 364 : 191 196

42. Mokrysz C, Landy R, Gage SH, et al. Are IQ and educational outcomes in teenagers related to their cannabis use? A prospective cohort study. Journal of Psychopharmacology. 2016; 6: 0269881115622241.

43. Meier MH, Caspi A, Ambler A, et al. Persistent cannabis users show neuropsychological decline from childhood to midlife. Proceedings of the National Academy of Sciences. 2012; 109(40): E2657-64.

44. Moore T, Zammit S, Lingford-Hughes, Barnes T, et al. Cannabis use and risk of psychotic or affective mental health outcomes: A systematic review. Lancet. 2007; 370: 319

45.Zammit S, Allebeck P, Andréasson S, et al. Self-reported cannabis use as a risk factor for schizophrenia in Swedish conscripts of 1969: historical cohort study, Brit Med J. 2002; 325: 1199

46. Hall W and Degenhardt L. The adverse health effects of chronic cannabis use. Drug Test Analysis. 2014; 6: 39-45

47. Aryana A, Williams MA. Marijuana as a trigger of cardiovascular events: speculation or scientific certainty?. International journal of cardiology. 2007; 118(2): 141-4.

48. Lee MHS \& Hancox RJ. Effects of smoking cannabis on lung function. Expert Review of Respiratory Medicine. 2011; 5(4): 537-547

49. Fitzcharles M, Ste-Marie PA, Häuser W, et al. Efficacy, tolerability, and safety of cannabinoid treatments in the rheumatic diseases: a systemic review of randomized controlled trials. Arthritis Care \& Research. 2016; 68(5): 681-688

50. Katchan V, David P, Shoenfeld Y. Cannabinoids and autoimmune diseases: A systematic review. Autoimmunity reviews. 2016; 15(6) :513-28.

51.Budney A and Hughes J. The cannabis withdrawal syndrome. Curr Opin Psychiat. 2006; 19: 233

52.Gunn JKL, Rosales CB, Center KE, et al. Prenatal exposure to cannabis and maternal and child health outcomes: a systematic review and meta-analysis. BMJ Open. 2016 ;6 : e009986 